\title{
Cointegration of causes of mortality as a possible measure of human ageing
}

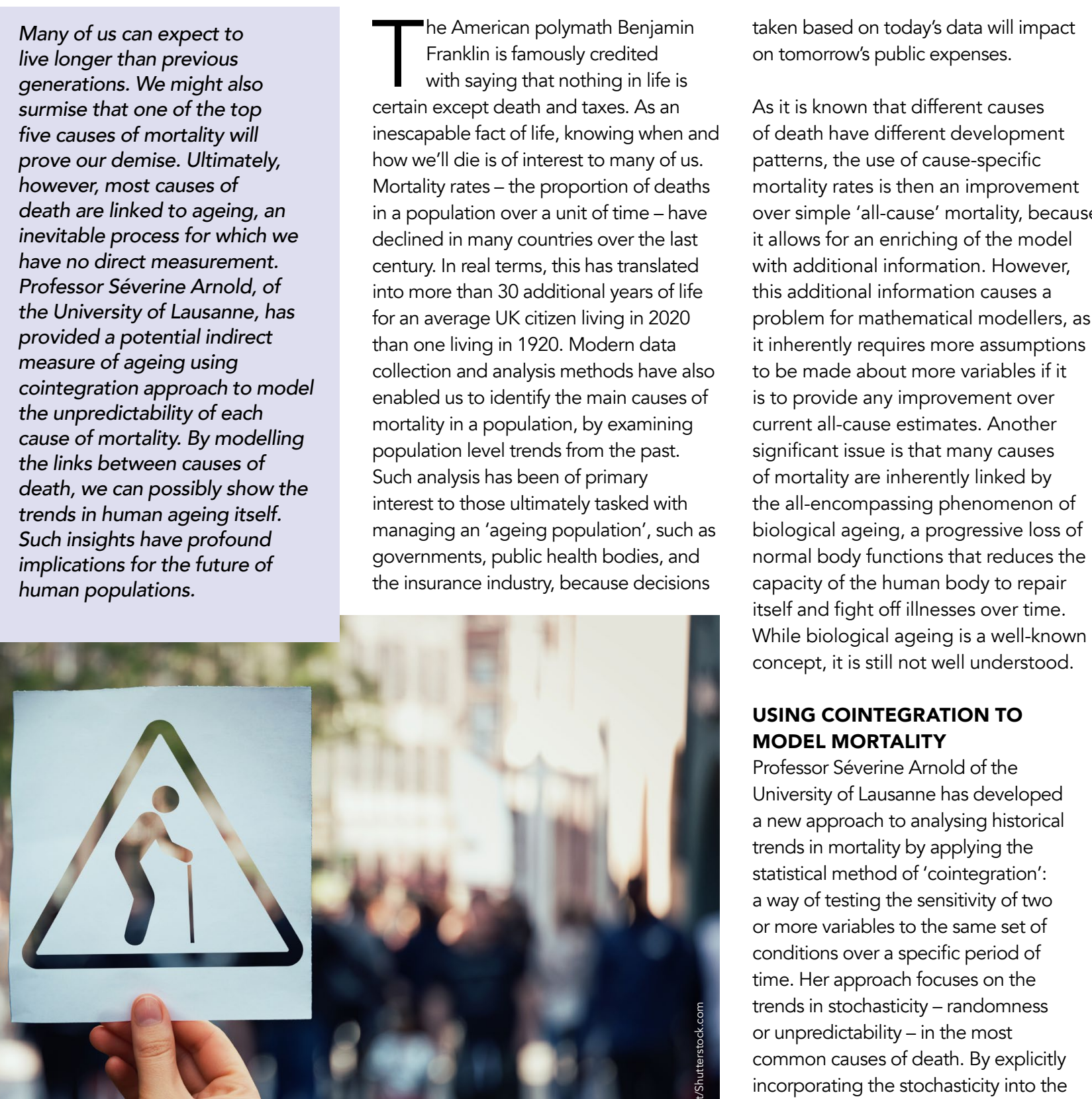

Many of us can expect to live longer than previous generations. We might also surmise that one of the top prove our domise. Ultimately however, most causes of death are linked to ageing, inevitable process for which we have no direct measurement. Professor Séverine Arnold, of the University of Lausanne, has provided a potential indirect measure of ageing using the unpredictability of to model cause of mortality. By modeling the links between causes of death, we can possibly show trends in human ageing itself. Such insights have profound implications for the future of human popu

The American polymath Benjamin Franklin is famously credited with saying that nothing in life is inescapable fact of life, knowing when and how we'll die is of interest to many of us Mortality rates - the proportion of death in a population over a unit of time - have declined in many countries over the last century. In real terms, this has translated into more than 30 additional years of life for an average UK citizen living in 2020 than one living in 1920. Modern data collection and analysis methods have also enabled us to identify the main causes of mortality in a population, by examining population level trends from the past. Such analysis has been of primary interest to those ulimately tasked with managing an 'ageing population', such as gove insurance industry becarse decisons

taken based on today's data will impact on tomorrow's public expenses.

As it is known that different causes patterns, the use of cause-specific mortality rates is then an improvement over simple 'all-cause' mortality, because it allows for an enriching of the model with additional information. However, this additional information causes a problem for mathematical modellers, as inherently requires more assumptions ts be made about more variables if it is to provide any improvement over current all-cause estimates. Another for mont issue is that many causes (the allencor iolo normaty apacity of the human body to repair self and fight offillnesses over time. While biological ageing is a well-known concept, it is still not well understood.

USING COINTEGRATION TO MODEL MORTALITY

Professor Severine Arnold of the new approach to analysing historica trends in mortality by applying the statistical method of 'cointegration': a way of testing the sensitivity of two or more variables to the same set of conditions over a specific period of time. Her approach focuses on the rends in stochasticity-randomness or unpredictability - in the most incorporating the stochasticity into the
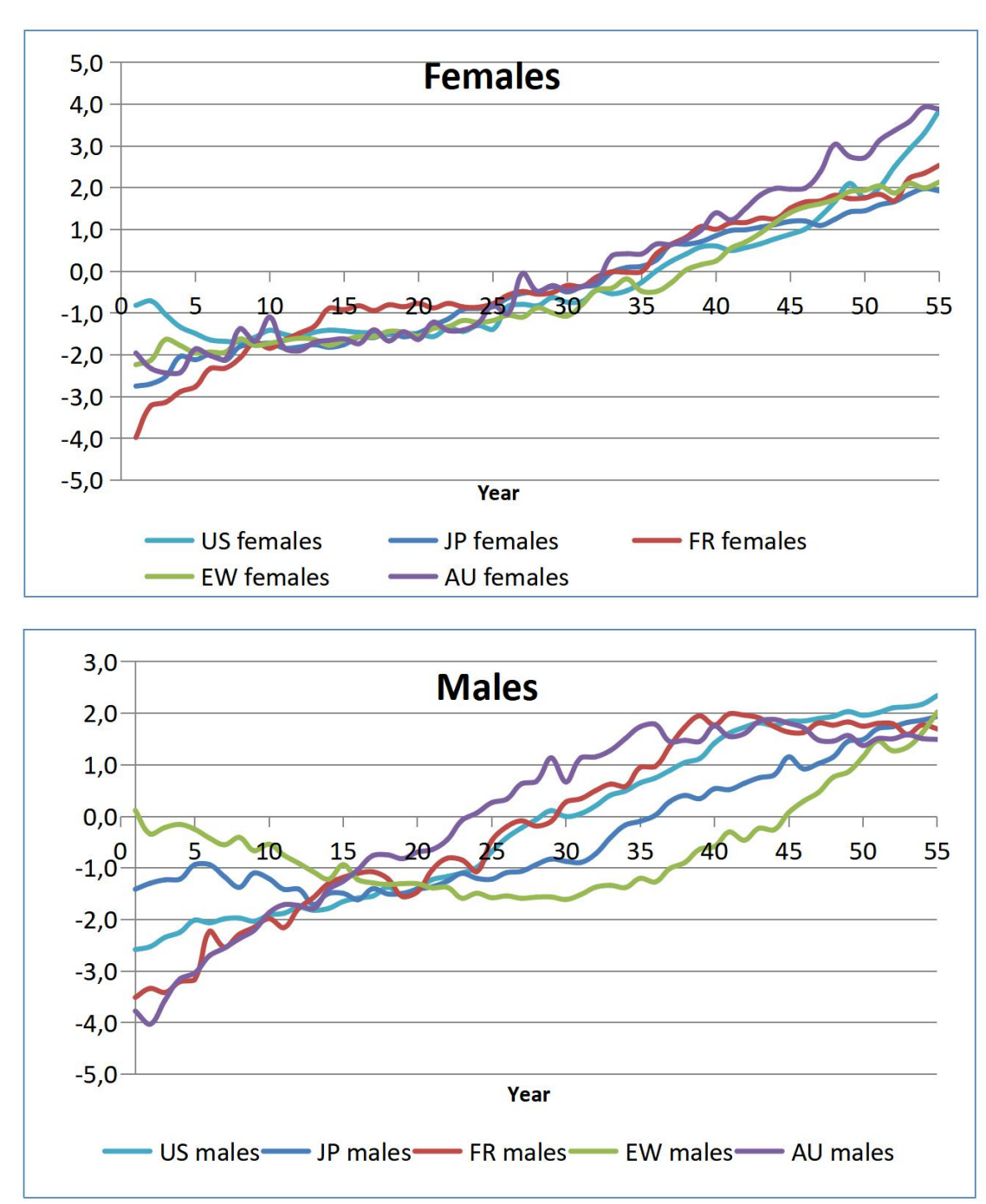
First principal component for each country, namely the primary connection between the causes of
death in each country. It's interesting to note the similarity between all countries. er time. In practice, this bypasses the (a) the true dependency structure between specific causes of mortality.

The central feature of the cointegration method is an assumption that the linear combination between two or more variables itself is stationary over time. In other words, that two different causes of mortality are inherently related in a fixed way over the course of time. Furthermore, vo variables equilirium between the the specific metric of a cointegration relation. Such metrics have been readily applied in the field of econometrics to other long-term trends in interest rates, consumpten, and ncome, but professor Amo has the potentia to reveal bon and short-term trends in the relations between specific causes of mortality Such trends could arise from changes in health care provision or lifestyle in different countries or from genetic differences in the biological causes of ageing in different populations. These changes might impact positively or negatively the cointegration relations. Establishing the cointegration relations of causespecific mortality in countries with simila socioeconomic backgrounds can provid model, Professor Improvements in the fit of statistical and ultimatelymove models is like improving the fit of a of different causes of death in different pattern for making a jumper.

towards the goal

trends in cause-specific mortality

able to model the . universal trends in mortality.

This new application of cointegration can be thought of as a fine-tuning tool that specifically accounts for the dynamic nature of specific variables, thereby making its predictions more closely fit the patterns seen in different human populations. Such improvements in the "fit' of statistical models is like improving The main pant for The main advantage of improving the statistical fiv va cointegration over other apprividulised risk factors, ss thas ti he unpedictabilin in the causes of dean

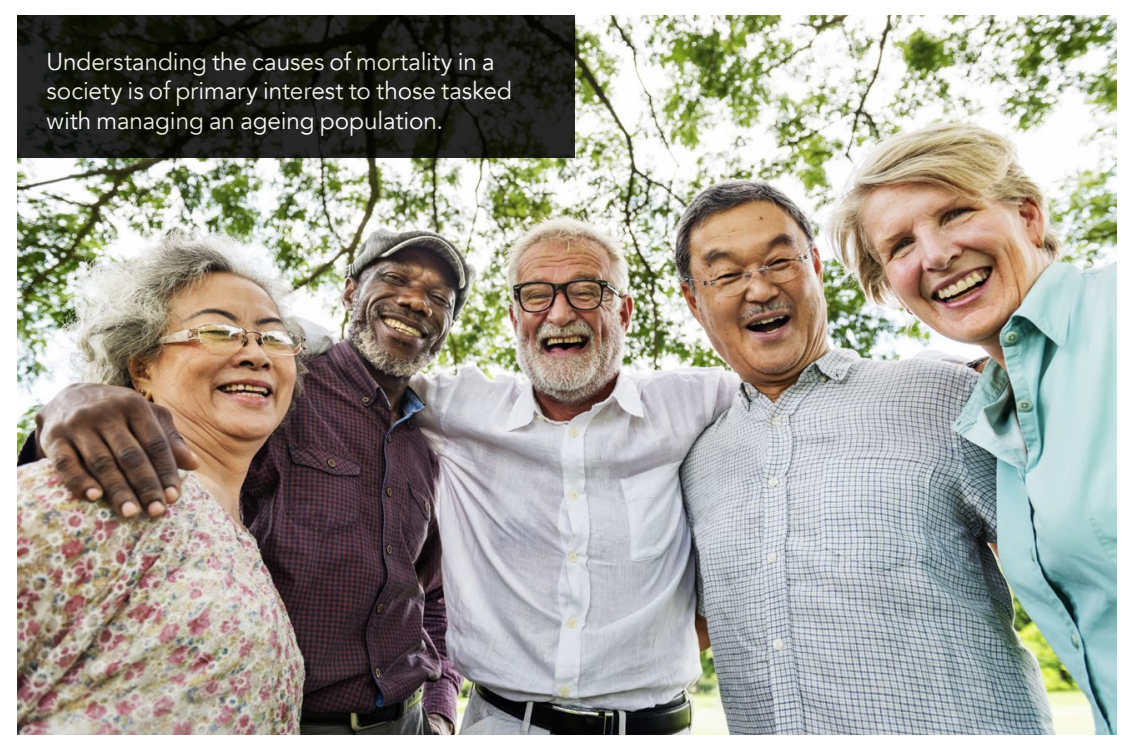




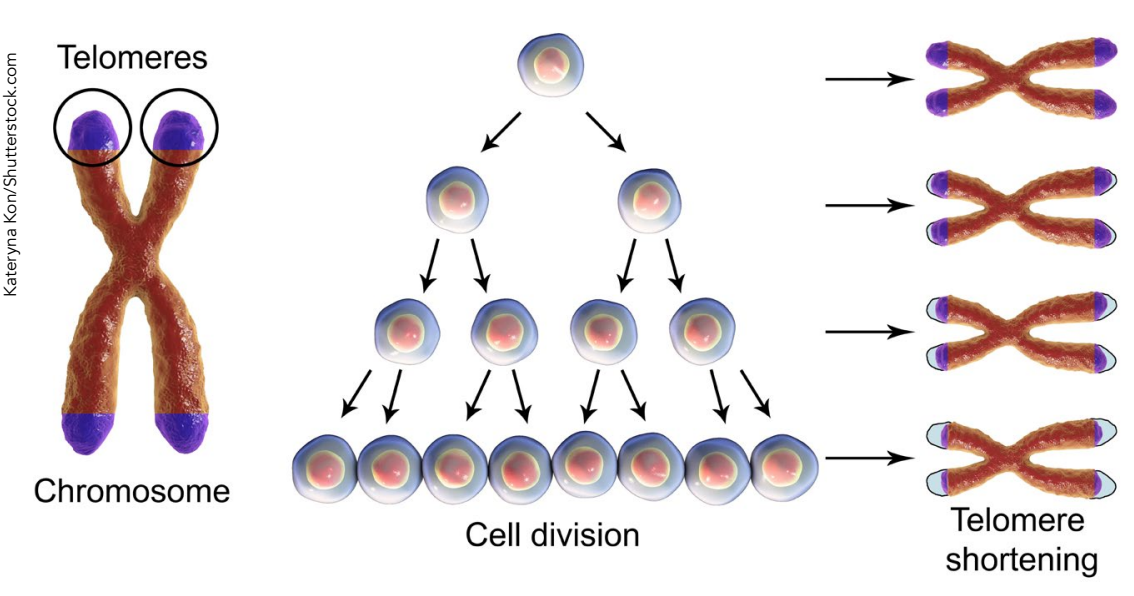

Telomere shortening is a key sign of ageing.

\section{DEPENDENCE BETWEEN}

CAUSES OF DEATH

Most recently, Professor Arnold

and colleagues have developed

cointegration methods further, by

examining the non-fixed part of the

of mortality and modelling these

trends between the sexes and across

different countries of comparable

development. They used data from the

World Health Organisation Mortality

Database to examine the rates of

mortality for infections/parasites,

cancer, circulatory diseases, respiratory

diseases, and external causes

(accidents and incidents) in males

and females in USA, Japan, France,

England and Wales, and Australia.

By identifying the sources of

stochasticity common to all five causes of mortality, Professor Arnold was able to statistically isolate them. Then she used principle-components analysis number of variables in a model to identify the primary connection betwe those five specific causes of mortality? and then between countries, in a two stage process.

At least one cointegration relation was observed between countries, suggesting that the five countries all shared some underlying feature of specific causes of mortality, most likely based on the universal features unique to the biologica processes of ageing. Interestingly, the stochastic factors were not cointegrated between the sexes, indicating important differences in the biological ageing of males and females that need to be acknowledged in
models for each.

Professor Arnold and her colleagues also models, improving the statistical fit of models to real data. In the wider sense, aspects of mortity rates and find? universal stochastic trends between internal, or biological, causes of mortality suggests that cointegration can bring us closer to modelling ageing itself. At present, cointegration can only show the historic trends in dependence between different causes of mortality, and until we can confirm that the trends identified match true biomarkers of ageing, this will past trends. Future reconciling of these to fully realise the potential of statistical modelling for tidentifing the biological processes of ageing themselves. If such methods come to prove a 'biological', rather than 'chronological

implications for individuals, as well as elations were primanty diven by from cancer, circulatory illnesses, and related to infections/parasites, or

If such methods come to prove a

'biological', rather than 'chronological' implications for individuals.

accidents and incidents. These so-called society more broadly. For example, endogenous factors (arising from within) how do we balance the inherent risks of appear to form consistent clusters in specific causes of mortality with those cointegration methods, confiming the related to more environmental causes potential for this method to measure of mortality, like air pollution and car the fundamental processes common accidents? Is it fair to penalise or reward to humans in different populations. an individual for their genetic lot in life? these insights can be direclly useful - These are

to those with an interest in refining
the assumptions behind mortality rate
public health bodies to address.

A

\section{Behind the Research}

\section{Professor Séverine Arnold}

E: Severine.Arnold@unil.ch T: +41216923372

W: hecnet.unil.ch/hec/recherche/fiche?pnom=sarnold\&dyn lang=en remain a retrospective examination of two indicators would enable researchers age, this could have profound

\section{Research Objectives}

The impacts of cause-specific mortality rates on financial systems.

\section{Detail}

\section{Address}

University of Lausanne, Faculty of Business and

Economics, Department of Actuarial Science, Quartier Swit-Cha, Deparment of Actualis Scince, Quasann

Séverine Arnold is Professor in Actuarial Science at the University of Lausanne, Switzerland. Her research focuses first on longevity risk/mortality modelling, with a particular interest in cause-specific mortality rates, second on social She also regularly cooperates with the International Labour Organization on projects related to insurance.

Funding

Swiss National Science Foundation for the project 'Cause-Specific Mortality Interactions' (project number

\section{Collaborators}

Co-author Viktoriya Glushko, Department of Actuarial Science, Faculty of Business and Econ

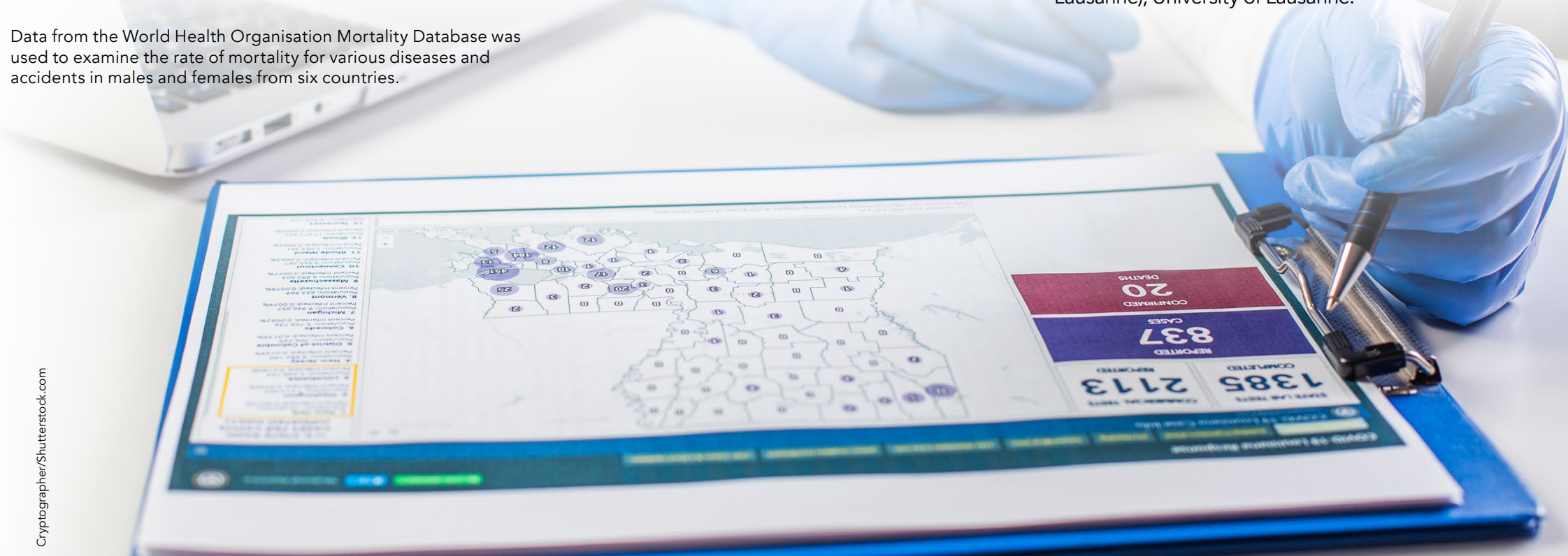

\section{References}

Arnold, S., and Glushko, V., (2021a) Cause-specific mortality rates: common trends and differences. Insurance Mathematics and Economics, 99, 294-308. doi.org/10.1016/1 insmatheco.2021.03.027

Arnold, S., and Glushko, V., (2021b) Short- and long-term dynamics of cause-specific mortality rates using cointegration

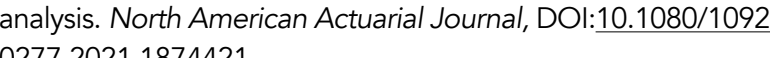
0277.2021 .1874421

Arnold-Gaille, S., and Sherris, M., (2016). International causespecific mortality rates: new insights from a cointegration

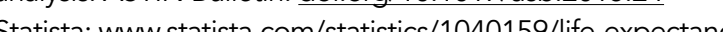
united-kingdom-all-time/ [Accessed 5.7.21]

\section{Personal Response}

How do you think the improvements in modelling from cointegration will affect the consumers of insurance industry products?

II More and more researchers around the world are trying to better understand ageing or our biological age. A key aspect of it is to look for biomarkers of ageing. We took a different, complementary approach, as we believe that mortality data. If we manage to show the link between these universal factors that we extracted through cointegration and ageing, that could potentially reveal how ageing processes evolved in the past and how then they might evolve in the future. If ageing is meant to be postponed, life as well as retirement schemes, health care systems, etc. The
whole society will need to be reorganised!

\section{Unil}

UNIL | Université de Lausanne HEC Lausanne 